\title{
Effect of polyunsaturated fatty acid supplementation on milk production - review on health effects and cow milk characteristics
}

\author{
Mwangi Paul Joseph Mwau, György Bázár, Tamás Tóth* \\ Kaposvár University, Faculty of Agricultural and Environmental Sciences, \\ H-7400 Kaposvár, Guba S. u. 40.
}

\begin{abstract}
The polyunsaturated fatty acids (PUFA) of the n-3 and n-6 group are important in the human body. It is therefore important that these fatty acids are consumed in the right amount and correct proportion so as to maintain a healthy physiological status in the body. Certain foods are naturally rich in these fatty acids, such as sea foods and some oilseeds. Fish and fish oils are rich in eicosapentanoic acid (EPA) and docosahexanoic acid (DHA) which are n-3 fatty acids, they play a crucial role in improving the physiological and health outcomes in conditions such as cardiovascular diseases, cancer, immune suppression and mental health. These fatty acids have also been shown to play beneficial role during pregnancy and lactation. Linolenic acid (LNA) which is abundant in oilseeds such linseed is a precursor of EPA and DHA in the human and therefore can be converted when need be, however the conversion is not very efficient and therefore cannot be used as a substitute. With the current deteriorating state of the global supply of fish and the high demand of energy causing diversion of resources to produce biofuels, the availability of these natural sources of $n-3$ and $n-6$ foods is growing ever scarce. Feeding of full-fat linseed and/or linseed oil has been shown to substantially increase the content of LNA in animal products such as meat, eggs and milk. On the other hand, fish oil supplementation in animal feeds also leads to a substantial increase in EPA and DHA to levels that can positive health effects to the public. Due to this potential to increase the amount of $n-3$ polyunsaturated fatty acids in animal products, it is seen as a simpler and cheaper way to deliver an increase in consumption to the wider public in a sustainable manner. This is due to the fact that products such as milk and eggs are more widely distributed and available in the market. Some challenges are of course present, such as negative effects due to the oxidative stability of polyunsaturated fatty acids which can have negative effects on rumen function and product organoleptic characteristics. To offset the problem of rumen biohydrogenation of PUFA, various methods of protecting the seed and fish oils have been devised, allowing for feeding even higher doses without impacting negatively on production and product quality.
\end{abstract}

Keywords: PUFA, fatty acid profile, cow, organoleptic

\section{INTRODUCTION}

Milk is recognized as one of the most nutritious food products from animals, because it contains most of the important macro- and micronutrients in adequate amounts essential for human growth and development. The nutrients are also of high nutritive value due to ease of digestion and absorption in the gastrointestinal tract, and hence the reason why it is the food of choice for children since their digestive system is still developing.

\footnotetext{
*CORRESPONDING AUTHOR

Kaposvár University, Faculty of Agricultural and Environmental Sciences, H-7401 Kaposvár, P.O. Box 16.; Tel.: 0036-82-505-800, Fax: 0036-82-320-175;

E-mail:toth.tamas@ke.hu
} 
The global production and consumption of milk and milk products has been on the rise, this has been in part due to an increase in economic growth and income levels especially in the developing and emerging countries. The per capita consumption of animal protein sources such as milk, meat and eggs has tremendously increased in developing countries, driven by income growth and urbanization. The milk consumption in the developing countries almost doubled from 1961-2007, during the same period egg consumption increased fivefold, while meat consumption tripled $(F A O, 2013)$. Cow milk accounts for $83 \%$ of the global milk production, the contribution of other animals is: goats $(2.4$ $\%$ ), sheep (1.4\%) and camels (0.3\%), buffaloes are however the most significant source of milk in South Asia accounting for slightly above half of the total milk production at $53 \%(F A O, 2013)$. Taking into account the clear significance of milk as part of diets globally, milk plays an important role in the nutrition and health of a huge population in the world. Recent increase in interest in the role of foods as nutraceuticals has led to research into possibilities of increasing biologically active agents in animal foods, and the greatest effort in animal feed research has been aimed at increasing the content of fatty acids with proven health benefits such as n-3 polyunsaturated fatty acids (PUFA), and conjugated linoleic acid (CLA) (Palmquist, 2009).

The milk fatty acid composition has been shown to be variable depending on the cows' diet, and due to this, opportunity to increase n-3 PUFA in the milk is possible by feeding feeds rich in these fatty acids, such as linseed and fish oils. Oil seed and fish oil (FO) supplementation in dairy cow diets seems to be a promising opportunity for producing dairy products with additional nutritive value, however assurance must be given to the consumers about the potential changes in the organoleptic properties of the product (Lerch et al., 2015).

The aim of this review is to look at the various literature and studies carried out with interest in the supplementation of cows with various sources and combinations of polyunsaturated fatty acids. The paper will focus on the supplementation effects on the milk fatty acid profile, the organoleptic properties of the milk and the health outcomes in the cows, as well.

\section{INTRODUCTION AND NOMENCLATURE OF FATTY ACIDS}

Fatty acids (FAs) are long chain monocarboxylic acids (C4-C36), they are the basic building blocks of some important fats. FAs are usually unbranched, have an even number of $\mathrm{C}$ atoms, and can either be saturated or un-saturated (contain double bonds). Odd chain acids are usually minor or trace components of 
plant and animal lipids, and are more abundant in bacterial lipids (Gunstone et al., 2007). There are over 1000 fatty acids known, with different chain lengths, configuration, position and degree of unsaturation, however only about 20 of them occur widely in nature. Among these FAs, oleic (C18:1 n-9), palmitic (C16:0) and linoleic acids (C18:2 n-6) make up 80\% of all commodity fats and oils (Gunstone et al., 2007).

Fatty acids are named systematically as carboxylic acid derivatives, numbering the chain from the carboxyl carbon (IUPAC-IUB, 1978). The -anoic ending of the saturated acid is changed to -enoic, -adienoic, -atrienoic, -atetraenoic, apentaenoic, and -ahexaenoic to indicate the presence of one to six double bonds, respectively. Systematic names for fatty acids are cumbersome in general use and both shorthand alternatives and trivial names are widely used. The shorthand names use two numbers separated by a colon for the chain length and number of double bonds, respectively, Octadecenoic acid with 18 carbons and one double bond is therefore, 18:1 while the trivial name would be Oleic acid (Gunstone et al., 2007).

\section{Saturated fatty acids}

These are FAs that do not contain double bonds in the carbon chain, they are generally even numbered with a general formula: $\mathrm{CH}_{3}\left(\mathrm{CH}_{2}\right)_{n} \mathrm{COOH}$. FAs that have 8-12 carbons are generally referred to as medium-chain fatty acids. Due to their specific physiological properties, they are absorbed and catabolized faster than long-chain fatty acids. Furthermore, FAs with 4-12 carbons are not very common and are mainly found in milk, coconut oil and palm oil. These are 4:0 butyric acid, 6:0 caproic acid, 8:0 caprylic acid, 10:0 capric acid, and 12:0 lauric acid (Leray, 2012). Long-chain fatty acids have 14 and above carbons, and the most important include, 14:0 myristic acid, 16:0 palmitic acid, and 18:0 stearic acid and are found in practically all vegetable oils and animal fats. 20:0 arachidic acid, 22:0 behenic acid, 24:0 lignoceric acid, and 26:0 cerotic acid are rarely found (Leray, 2012)

\section{Unsaturated fatty acids}

A wide variety of unsaturated FAs have either an alkenic chain (with one or more double bonds) or an acetylenic chain (with one or more triple bonds). Those with alkenic chains are classified as either monounsaturated (monoene) or polyunsaturated (polyene) (Leray, 2012). 


\section{Monounsaturated fatty acids}

Straight chain, cis isomers of monounsaturated Fas with even number of carbons are a common constituent of many lipids and commodity oils, trans isomers are rare components in natural oils and fats. The most common monounsaturated FA is oleic acid (C18:1), it is found in abundance in most plant and animal lipids and is the major fatty acid in olive oil (70-75 \%) and a variety of other nut oils such as macadamia, pistachio, almond, hazel nuts, and pecan contain 50 to over $70 \%$ (Gunstone et al., 2007). Since the elongation of the FA chain is carried out starting from the carboxyl group, the double bonds are counted starting from the final methyl group, this determines the metabolic family, noted by " $n-x$ ", whereby " $n$ " is the number of carbons in the chain and " $x$ " is the position of the last double bond, for example; linoleic acid is named $18: 2 n-6$ because like all FAs of the $n-6$ family, the last double bond is separated from the final methyl group by six carbons (Leray, 2012).

Other examples of monounsaturated FAs myristoleic acid (C14:1 n5), palmitoleic acid (C16:1 n7) found in fish and marine mammal fats, vaccenic acid (C18:1 n7) present in animal fats and butter, physeteric acid (C14:1 n9), discovered in fats of dolphin and whale and in the retinas of mammals, petroselinic acid (C18:1 n12), erucic acid (C22:1 n9), gadoleic acid (C20:1 n11). Transisomers of oleic acid are also in existence such as elaidic acid (trans 18:1 n9), and trans vaccenic acid (trans 18:1 n7). The trans vaccenic acid is the most abundant trans FA in dairy products, it is formed as a results of bacterial biohydrogenation in the rumen (Gunstone et al., 2007). Polyunsaturated fatty acids.

Polyunsaturated fatty acids (PUFAs) occur in a variety of structures, they have from two to nine double bonds distributed in various positions along the carbon chain (Leray, 2012). Most PUFAs with two or more double bonds occur in a characteristic methylene-interrupted pattern of unsaturation whereby one $-\mathrm{CH}_{2}$ - group is between two cis double bonds, this is due to the action of specific desaturase and chain-elongase enzymes (Gunstone et al., 2007). Palmquist (2009) in his review describes, that the double bond position is indicated by the position of the first carbon of the bond, and most naturally occurring PUFAs have the double bond in the cis, cis 1,4 pentadiene structure (multiple double bonds separated by a methylene group). It should be noted that the PUFAs of the n- 6 and n-3 series are considered as essential fatty acids (EFA) in human and also to various degrees in all animals (Palmquist, 2009). The precursor of the $n-6$ series, C18: 2 n 6 linoleic acid, and the precursor of the 
n-3 series, C18:3 n3 linolenic acid, are of vegetable origin and are the most essential fatty acids in human (Leray, 2012). The concept of fatty acids that are essential was first described by G. Burr when he showed that some fatty acids had special food value. For instance, in 1929, it was shown that classical skin lesions and symptoms of physiological deficiency including kidney degeneration and death could be reversed by supplementing the diet with lard, reviewed by (Palmquist, 2009). EFA are primarily found in phospholipids at the oil-water interphase, this exhibits the amphiphilic nature of the FAs and the important functional role of phospholipids in membranes. The membrane phospholipids have mainly saturated fatty acids concentrated at the sn-1 position on the glycerol molecule, while the sn- 2 position contains mainly longchain PUFA (Palmquist, 2009). Linoleic acid (C18:2 n6) is present in most plant oils and in high amounts (>50 \%) in corn, sunflower, soybean, and safflower oils; $\gamma$-linolenic acid (18:3 n3) is abundant in plant oils such as, borage, blackcurrant, evening primrose, and echium; other n-6 FAs such as arachidonic acid (C20:4), and dihomo- $\gamma$-linolenic acid (C20:3 n3) are abundant in animal tissues and act as precursors to biologically active chemicals such as PG2 and PG1 prostaglandins, respectively (Gunstone et al., 2007). $\alpha$-linolenic acid (C18:3 n3) is an abundant n-3 fatty acid found mainly in plants leaves and seed oils, it is abundant in linseed oil (>50\%), and perilla oil (65\%), chlorophyll lipids in leaves contain $50 \% \alpha$-linolenic acid; stearidonic acid (C18:4 n3) is a minor component of animal and fish oil and is found in some seed oils; the n-3 PUFAs eicosapentanoic acid (C20:5 n3, EPA) and docosahexanoic acid (C22:6 n3, DHA) have important nutritional significance, and are found mainly in marine fish, shelled fish and fish oils (Gunstone et al., 2007). Evidence in research has shown that long-chain n-3 PUFA have important bioactive properties that are known to reduce risk factors for diseases associated with the cardiovascular system, diabetes and cancer, however, the mechanism through which n-3 FAs affect intermediate metabolism is complex and involves multiple processes (Palmquist, 2009).

\section{IMPORTANCE OF ESSENTIAL FATTY ACIDS IN THE HEALTH OF COWS}

The n-3 and n-6 essential fatty acids (EFA) are important for the normal physiological functioning of humans and all domestic animal species. The increased interest in the potential health benefits of these FAs to humans, and the possibility to increase them in animal products through feeding, has led to a renewed interest (Palmquist, 2009). Additionally, research has also shown that the EFA also have beneficial properties to the cow's health and in particular 
improve the reproductive performance. EFA are mainly found in phospholipids at the oil-water interphase reflecting the amphiphilic nature of the molecules and the important function that phospholipids play in cell membranes (Palmquist, 2009). A study where different dietary levels of fat supplementation (low and high) was given to high producing dairy cows, and the production and development of oocytes were examined showed that high number of small and medium-sized follicles were observed in the low-fat group. However, the high-fat group had a significantly improved blastocyst production and quality from matured and cleaved oocytes (Fouladi-Nashta et al., 2007). Additionally, the high dietary fat improved embryo quality through an increase in total and trophectoderm cell numbers in the blastocysts. During early lactation, high producing dairy cows suffer from a negative energy balance, which also coincides with the period when the next conception should occur as part of management strategy to optimize long-term milk production (Palmquist, 2009). Insufficient supply of energy at this time leads to poor reproductive performance characterized by delayed onset of estrous cycle, reduced oocyte quality, which in turn results in low conception rates, high rate of early embryonic death or both (Fouladi-Nashta et al., 2007). The same authors reported significant negative effects of milk yield, dry matter intake (DMI), metabolizable energy (ME) intake and starch intake on the production of blastocysts in low-fat diet group (200 g/day), but not in the high-fat diet group (800 g/day). Fat provision cushioned the oocytes from the effects of energy challenges faced by high producing dairy cows leading to improved embryonic development potential.

In their review Wathes et al. (2007) indicate that twenty carbon PUFAs are the precursors of a group of physiological active compounds known as eicosanoids which include prostaglandins (PGs), thromboxanes, leukotrienes, and lipoxins. Series-1 PGs are produced from dihomo-gamma-linolenic acid (DGLA), series-2 from arachidonic acid (AA), while series-3 PGs are derived from EPA. It is their view that there is evidence that dietary long-chain PUFAs have the capability to influence the type and amount of PGs produced by various tissues; by acting as substrates for and competitive inhibitors of cyclooxygenation and by altering the cell concentration or expression of various important enzymes. For instance, an increase in n-3 PUFA can reduce total PG synthesis and shift the balance of PGs in the tissue towards the series-3. For successful implantation of the conceptus in the uterus to occur, it must be able to inhibit PG release from the uterus. Pre-implantation mortality of embryos suggests that the embryos are not capable of inhibiting PGF2 $\alpha$ release; leading to continued release causing the Corpus luteum to regress, and termination of 
the pregnancy (Fouladi-Nashta et al., 2007). In order for a successful pregnancy to occur in cows, there are suitable conditions that need to be met which include: ovulation of a competent oocyte, insemination at the correct time, and an ideal hormonal balance between estradiol and progesterone during the follicular and luteal phases of the estrous cycle, additionally the embryo will need to develop adequately to prevent luteolysis, and there is evidence that these events can be influenced by dietary PUFAs (Fouladi-Nashta et al., 2007).

\section{EFFECT OF DIETARY FAT SUPPLEMENTATION ON COW MILK FATTY ACID PROFILE}

In an experiment carried out using low levels of fish oil (FO) $105 \mathrm{~g} /$ day, and $255 \mathrm{~g} /$ day of sunflower oil (SO) separately and in combination (255 g/day of $\mathrm{SO}+52.5 \mathrm{~g} /$ day of FO) supplemented to cows on pasture. The milk concentration of C6:0, C8:0, C12:0 ( $\mathrm{P}<0.01), \mathrm{C10}: 0$ and C16:0 ( $<<0.001)$ decreased, while there was an increased concentration of $\mathrm{C} 18: 0(\mathrm{P}<0.05), \mathrm{C} 18: 1$ trans-9 $(\mathrm{P}<0.01), \mathrm{C} 18: 1$ trans-11 $(\mathrm{P}<0.001), \mathrm{C} 18: 2$ cis -9 , trans-12 $(\mathrm{P}<0.001)$ and $\mathrm{C} 18: 2$ cis-9, trans-11 CLA $(\mathrm{P}<0.01)$ (Murphy et al., 2008). In this study there were differences in sunflower oil and fish oil effect on some fatty acid concentrations, FO led to a greater proportion of $\mathrm{C} 4: 0(\mathrm{P}<0.05), \mathrm{C} 18: 1$ trans-9 and C18:1 trans$11(\mathrm{P}<0: 01)$, and C18:2 cis-9, trans-11 CLA $(\mathrm{P}<0.05)$, while the proportion of C18:0 and C18:3 cis-9, cis- 12 , cis-15 was greater $(\mathrm{P}<0.01)$ on SO. Supplementing with a mixture of the two oils compared with offering them separately decreased the concentrations of $\mathrm{C4:0}(\mathrm{P}<0.001)$ and $\mathrm{C6:0}(\mathrm{P}<0.05)$ and increased the concentrations of $\mathrm{C18:0}(\mathrm{P}<0.01)$ and cis-9, trans-11 CLA $(\mathrm{P}<0.05)$. The results confirmed that the concentration of C18:2 cis-9, trans-11 CLA can be increased further, from an already relatively high concentration in milk from pasture, by offering supplements containing a low level of fish oil either alone or in combination with sunflower oil (Murphy et al., 2008).

Fat supplementation in dairy diets may have adverse effects such as; reduced feed intake, reduction in plasma glucose, and increased body fat mobilization which in turn may have negative health impact on the cow and on milk production (Juchem et al., 2008). To offset the negative impact of increased supplementation of unsaturated fat sources, the use of rumen protected fats such as calcium salts ( $\mathrm{CaS}$ ) of fats has been explored as an alternative. CaS provide a degree of protection from microbial biohydrogenation in the rumen (Weiss and Wyatt, 2004), CaS therefore provide a viable technology to reduce the effect on the rumen and to increase intestinal digestibility of FAs, modify the FAs that reach the small intestines and ultimately have an impact on the 
milk FA profile (Juchem et al., 2008). Juchem et al. (2008) conducted a study to determine the effect of different sources of FAs fed as CaS of fish oil and palm oils (CaSFO) or tallow on the performance of dairy cows. The study was designed to evaluate the effect of dietary EPA and DHA supplementation on lactational performance and milk FA composition. To increase the supply of dietary EPA and DHA to dairy cows while avoiding their potential negative effects on rumen fermentation, those FAs were incorporated into a calcium salt of fish oil combined with palm oil. Both treatment groups received a similar diet with the only difference being the supplemental fat source, which was included in the total mixed ration (TMR) to supply equal amounts of FA from CaSFO or tallow. Cows fed CaSFO had increased proportion of EPA, DHA, cis-9, trans-11 CLA, C18:1 trans-9, and C18:1 trans-11 FA $(\mathrm{P}<0.01)$ in milk fat. The results in this experiment showed that feeding of CaSFO altered the milk FA composition, and increased the proportion of EPA and DHA by $13.1 \%$ and $71.4 \%$ respectively.

Kairenius et al. (2015) showed results of four multiparous lactating cows feeding grass silage based diet supplemented with fish oil (FO, ultra-refined herring and mackerel oil) at the rate of 0, 75, 150 and $300 \mathrm{~g} /$ day. The FO supplementation modified the milk fat composition characterized by a linear decrease in 4-14 carbon saturated fatty acids (SFA), 16:0, 18:0, total SFA, and 18:1 $(\mathrm{P}<0.05)$, and a linear or quadratic increase in total 16:1, 16:2, trans 18:1, total 18:2, total CLA, 20:5n-3, 22:5n-3, 22:6n-3, and total trans FA $(\mathrm{P}<0.05)$. There was however no significant effect on milk C18:1, linoleic (C18:2n-6) and linolenic acid (C18:2n-3) proportion ( $\mathrm{P}>0.05)$.

Fish oil composition is highly variable depending on the fish species, season and geographical variation, ranging from 4 to $32 \%$ for EPA, 2-25 \% for DHA, and for other major FAs i.e. C14:0, C16:0, C16:1, C18:1, C20:1, C22:1 (Chilliard et al., 2001). Studies on rumen EPA and DHA hydrogenation both in vivo and in vitro have given contradictory results, however EPA and DHA seem to undergo hydrogenation to a large extent but less than PUFAs, and EPA is hydrogenated more than DHA (Chilliard et al., 2001). Chilliard et al. (2001) observed that a low supply of 50-100 g/day of fish oil led to a decrease in milk fat content, and a mean decrease of milk fat content by $9.1 \mathrm{~g} / \mathrm{kg}$ was also observed when a daily inclusion rate of 180-145 g of fish oil was made to the diet of dairy cows. There was a slight decrease in the percentage of C4-C14 FA due to a slightly higher decrease in these FA proportional to the total fat secretion. More marked decrease was seen when milk fat content was sharply decreased (more than 10 $\mathrm{g} /$ day). Furthermore, in almost all trials reviewed there was a very large increase in the percentage of trans-C18:1 and to a lower extent in the percentage 
of trans-C16:1. The increase in trans-C18:1 percentage mainly due (for 74-82 $\%)$ to the trans-11 isomer together with small increases in trans-6, trans-9, trans-10 and -11 C18:1 isomers. The milk CLA content increased sharply from 0.2-0.6 \% in control diets to 1.5-2.7 \% in supplemented diet, with as little supplementation as 200-300 g/day of marine oil. The increase was almost exclusively due to rumenic acid cis-9, trans-11 CLA (Chilliard et al., 2001). Marine oils have been extensively studied due to the potential health benefits by increasing n-3 FA and CLA concentration in milk and reduction in the milk fat content, they sharply decrease fat content, and almost all milk FAs particularly oleic, palmitic and stearic acids. On the other hand they increase secretion of trans-C18:1, CLA, EPA, DHA, however the transfer efficiency to milk of EPA and DHA is very low at less than 3-5\% (Chilliard et al., 2001).

In an 8-week trial (AbuGhazaleh and Holmes, 2007) fish oil and sunflower oil were added to the diet of partially grazing Holstein cows. The amount of supplementation was $100 \mathrm{~g} /$ day FO and $300 \mathrm{~g} /$ day of SFO, in this study the milk production, milk fat percentage, milk fat yield and milk protein yield were not affected by the dietary treatments. The proportion of cis-9, trans-11 CLA and vaccenic acid in milk fat were significantly higher for cows fed the oil-supplemented diet over the 8 weeks of oil supplementation. Trans-11 18:1 (vaccenic acid, VA), is a precursor of the biohydrogenation of both linoleic and linolenic acid in the rumen, in the tissues VA can be converted to cis-9, trans-11 CLA by the action of the $\Delta 9$-desaturase enzyme (AbuGhazaleh and Holmes, 2007). Supplementation of fish oil and sunflower oil separately led to significant increase in milk CLA content, however studies have shown that a blend of fish oil and extruded sunflower oil was more efficient in the enhancement of VA and cis-9 trans-11 CLA than when fed separately (Whitlock, 2002). In another study where a combination of fish oil with other oil sources which were high in either stearic acid (rumo-fat $64.2 \%$ stearic acid), oleic acid (sunflower seeds $83.9 \%$ oleic acid), linolenic acid (flax seeds $50.1 \%$ linolenic acid), or linoleic acid (sunflower seeds $60 \%$ linoleic acid); the study concluded that feeding a high linoleic acid fat source with fish oil most effectively increased proportion and yields of milk cis-9, trans-11 CLA and VA (Kalscheur, 2003).

Ferlay et al. (2013) reported that the FA composition was influenced by increasing the amount of linseed in the diet, the SFA decreased $(p<0.001)$ linearly with increased amounts of extruded linseed inclusion in the diet (0-15\%). On the other hand, the milk MUFA, PUFA, and total trans FAs increased linearly $(\mathrm{p}<0.001)$, there was also a linear increase in the total $n-3 \mathrm{FAs}(\mathrm{p}<0.001)$ and a reduction in the $n-6: n-3$ ratio in a linear manner as well. The percentage of cis- 9 trans-11 CLA increased $(p<0.05)$ in both a linear and quadratic manner, 
whereby the highest value was reached when extruded linseed was at $10 \%$, then decreasing between 10 and $15 \%$. The authors concluded that extruded linseed supplementation can alter the FA composition of milk, with an increase in potentially beneficial n-3 FAs, cis- 9 trans-11 CLA and a decrease in SFA. Extruded linseed also led to an increase in milk trans FAs percentage. Increasing extruded linseed by $2.1 \%$ and $4.3 \%$ respectively in two experimental diets of Holstein cows on a total mixed ration diet based on corn silage and concentrates led to a linear decrease in saturated fatty acids (C6-C14), and palmitic acid (C16:0). Increasing linseed dose led to an increase in the quantity of total polyunsaturated FAs, particularly C18:3 (three-fold increase). In contrast, quantity of C18:2 decreased, whereas quantity of cis-9 trans-11 CLA increased only with the $2.1 \%$ extruded linseed treatment (Hurtaud et al., 2010).

\section{EFFECT OF FAT SUPPLEMENTATION ON THE ORGANOLEPTIC PROPER- TIES OF MILK}

The supplementation of dairy cow diets with fats with a high percentage of PUFA has been shown to be an effective way of enriching milk with these FAs. However, with an increase in PUFA the risk of milk spoilage due to oxidation must be put into consideration, it is also necessary to be aware of the consumer preferences in terms of the organoleptic changes that may occur due to these supplementations. Therefore, to assure consumer acceptance of the milk and milk products, knowledge of the effects of fish oils and seed oils addition to dairy diets on the sensorial properties of the milk and its products is required (Lerch et al., 2015).

Lerch et al. (2015) examined the effect of extruded linseed supplementation ( $5 \%$ of additional fat to DMI) to dairy cows on a diet based on corn silage, on the sensorial properties of milk and cheese. In their study, there was no effect $(\mathrm{P}>0.10)$ on the sensorial properties of the bulk raw milk when assessed by descriptive tests. All the scores for off-flavor and odors (metallic taste, fishy odor and flavor) relative to lipolysis and oxidation remained undetected by the panel and were unaffected by extruded linseed, even when analyzed with triangular test, the trained panelists did not detect difference between the control and the supplemented group ( $P>0.10)$. Additionally, in another study where linseed oil at $3 \%$ of additional oil in DMI was supplemented in a concentrate or grass silage based diets had no effect on the organoleptic properties (Saliba et al., 2014). Hurtaud et al. (2010) observed no significant effect in the sensorial properties (color, smell, and flavor) of butter produced from milk, when they supplemented the diet of dairy cows with increasing amounts 
of extruded linseed ( $2.1 \%$ and $4.3 \%$ of the ration on a dry matter basis).

Cows were fed a supplement of calcium salts of palm and fish oil $(2.7 \%$ CaPFO), alone or in combination with extruded full-fat soy beans (5 \% ESB) or soy bean oil ( $0.7 \%$ SO) in a trial by Allred et al. (2006). They observed that milk had a significant enhancement of CLA, VA and total n-3 FA in all the diet combinations. However, a trained sensory panel did not observe any off flavors in milk from all treatments, and the overall quality was the same. The same research observed some oxidized flavor when experimental milk was used to prepare cheese especially for CaPFO + SO combined group. In a separate study where $2 \%$ soybean oil and $1 \%$ fish oil were supplemented to cows, the milk was then standardized to $2 \%$ fat, pasteurized, homogenized and stored in plastic containers at $4{ }^{\circ} \mathrm{C}$, oxidation was also induced by exposing half of the container to light (Lynch et al., 2005). Testing was conducted at 1, 7, and 14 days post pasteurization using triangle tests by untrained panelists. Although the levels of VA, cis-9 trans-11 CLA and degree of FA unsaturation were significantly elevated, the sensory evaluation indicated that the panelists found no flavor differences between the experimental milks and the control. Furthermore, there was no difference in the susceptibility to development of oxidized off flavors between the control and experimental milks even when oxidation was induced through exposure to light.

Forty-nine early-lactation Holstein Friesian cows were fed total mixed rations containing 0 (control) or $45 \mathrm{~g} / \mathrm{kg}$ (on dry matter basis) of a mixture (1:2 wt/wt) of fish oil and sunflower oil during two consecutive 7-day periods to produce a control and CLA-enhanced milk, respectively (Jones et al., 2005), in this study the control and experimental milks were used to produce ultra-heat treated milk (UHT), butter and cheese. The organoleptic properties of the produced products were analyzed by an experienced test panel using a triangle test. The study observed there was a significant difference between the experimental UHT milk and the control milk (23 out of 36 observations correctly identified the different milk samples), the control and experimental butters stored at $8{ }^{\circ} \mathrm{C}$ were also found to be significantly different. However, no off flavors or rancidity was detected by any of the panelists.

\section{CONCLUSIONS}

Intake of n-3 fatty acids is shown to be important for the normal physiological functioning of dairy cows, especially with regard to reproductive health which has the potential of increasing the productivity and longevity of the cow. Furthermore, consumption of adequate amounts of n-3 FAs through intake of fish oil FAs is not sustainable due to diminishing fish resources. However, there is 
potential to increase the amounts of n-3 FAs in milk and other animal products hence presenting an opportunity for increased intake of the beneficial FAs in population. It is important to be cognizant of the negative implication of feeding high amounts of PUFAs in dairy cow diets, and importantly to put into consideration the organoleptic changes that would occur and their impact on consumer acceptability of the end product.

\section{ACKNOWLEDGEMENTS}

Authors would like to express their sincere gratitude to the Ministry of Agriculture of Hungary (MoAH) and the Food and Agriculture Organization of the United Nations (FAO) for supporting this study by awarding the FAO-Hungarian Government Scholarship to author P. Mwau.

\section{REFERENCES}

AbuGhazaleh, A.A., Holmes, L.D. (2007) Diet supplementation with fish oil and sunflower oil to increase conjugated linoleic acid levels in milk fat of partially grazing dairy cows. J Dairy Sci, 90(6). 28972904. DOI: $\underline{10.3168 / j d s .2006-684}$

Allred, S.L., Dhiman, T.R., Brennand, C.P., Khanal, R.C., McMahon, D.J., Luchini, N.D. (2006) Milk and cheese from cows fed calcium salts of palm and fish oil alone or in combination with soybean products. J Dairy Sci, 89(1). 234-248. DOI: 10.3168/jds.s0022-0302(06)72088-4

Chilliard, Y., Ferlay, A., Doreau, M. (2001) Effect of different types of forages,animal fat or marine oils in cows diet on milk fat secretion and composition,especially conjugated linoleic acid (CLA) and polyunsaturated fatty acids. Livestock Prod Sci, 70(1-2). 31-48.

DOI: $10.1016 / s 0301-6226(01) 00196-8$

FAO. (2013). Milk and dairy products in human nutrition. Retrieved from http://www.fao.org/docrep/018/i3396e/i3396e.pdf

Ferlay, A., Doreau, M., Martin, C., Chilliard, Y. (2013) Effects of incremental amounts of extruded linseed on the milk fatty acid composition of dairy cows receiving hay or corn silage. J Dairy Sci, 96(10). 6577-6595. DOI: $\underline{10.3168 / j \mathrm{ds} .2013-6562}$

Fouladi-Nashta, A.A., Gutierrez, C.G., Gong, J.G., Garnsworthy, P.C., Webb, R. (2007) Impact of dietary fatty acids on oocyte quality and development in lactating dairy cows. Biology Reprod, 77(1). 9-17. DOI: $10.1095 /$ biolreprod.106.058578

Gunstone, F.D., Harwood, J.L., Dijkstra, A.J. (2007) The Lipid Handbook. CRC Press, Taylor \& Francis Group, New York, USA, pp. 791.

Hurtaud, C., Faucon, F., Couvreur, S., Peyraud, J. (2010) Linear relationship between increasing amounts of extruded linseed in dairy cow diet and milk fatty acid composition and butter properties. J Dairy Sci, 93(4). 1429-1443. DOI: 10.3168/jds.2009-2839

IUPAC-IUB Commission on Biochemical Nomenclature (1978) The nomenclature of lipids. J Lipid Research, 19. 114-128. http://www.jlr.org/content/19/1/114.full.pdf+html

Jones, E.L., Shingfield, K.J., Kohen, C., Jones, A.K., Lupoli, B., Grandison, A.S., Beever, D.E., Williams, C.M., Calder, P.C., Yaqoob, P. (2005) Chemical, physical, and sensory properties of dairy products enriched with conjugated linoleic acid. J Dairy Sci, 88(8). 2923-2937.

DOI: $10.3168 /$ jds.S0022-0302(05)72973-8

Juchem, S.O., Santos, J.E.P., Cerri, R.L.A., Chebel, R.C., Galvão, K.N., Bruno, R., DePeters, E.J., Scott, T., Tatcher, W.W., Luchini, D. (2008) Effect of calcium salts of fish and palm oils on lactational performance of Holstein cows. Anim Feed Sci Technol, 140(1-2). 18-38. 
DOI: $10.1016 /$ i.anifeedsci.2007.01.018

Kairenius, P., Ärölä, A., Leskinen, H., Toivonen, V., Ahvenjärvi, S., Vanhatalo, A., Huhtanen, P., Hurme, T., Griinari, J.M., Shingfield, K.J. (2015) Dietary fish oil supplements depress milk fat yield and alter milk fatty acid composition in lactating cows fed grass silage-based diets. J Dairy Sci, 98(8). 56535671. DOI: $\underline{10.3168 / j d s .2015-9548}$

Kalscheur, K.F. (2003) Milk conjugated linoleic acid response to fish oil supplementation of diets differing in fatty acid profiles. J Dairy Sci, 86(3). 944-953.

DOI: $10.3168 / j d s . s 0022-0302(03) 73677-7$

Leray, C. (2012) Introduction to Lipidomics: From Bacteria to Man. CRC Press, Taylor \& Francis Group, New York, USA, pp. 332.

Lerch, S., Ferlay, A., Graulet, B., Cirié, C., Verdier-Metz, I., Montel, M.C., Chilliard, Y., Martin, B. (2015) Extruded linseeds, vitamin $\mathrm{E}$ and plant extracts in corn silage-based diets of dairy cows: Effects on sensory properties of raw milk and uncooked pressed cheese. Int Dairy J, 51. 65-74. DOI: 10.1016/j.idairyj.2015.07.006

Lynch, J.M., Lock, A.L., Dwyer, D.A., Noorbakhsh, R., Barbano, D.M., Bauman, D.E. (2005) Flavor and stability of pasteurized milk with elevated levels of conjugated linoleic acid and vaccenic acid. J Dairy Sci, 88(2). 489-498. DOI: 10.3168/jds.s0022-0302(05)72711-9

Murphy, J.J., Coakley, M., Stanton, C. (2008) Supplementation of dairy cows with a fish oil containing supplement and sunflower oil to increase the CLA content of milk produced at pasture. Livestock Sci, 116(1-3). 332-337. DOI: 10.1016/i.livsci.2008.02.003

Palmquist, D.L. (2009) Omega-3 fatty acids in metabolism, health, and nutrition and for modified animal products foods. Professional Anim Scientist, 25(3). 207-249. DOI: $10.15232 / s 1080-7446(15) 30713-0$

Saliba, L., Gervais, R., Lebeuf, Y., Vuillemard, J.C., Fortin, J., Chouinard, P.Y. (2014) Effect of feeding linseed oil in diets differing in forage to concentrate ratio: 2. Milk lactone profile. J Dairy Research, 81(1). 91-97. DOI: $10.1017 / s 0022029913000708$

Wathes, D.C., Abayasekara, D.R.E., Aitken, R.J. (2007) Polyunsaturated fatty acids in male and female reproduction. Biology Reprod, 77(2). 190-201.

DOI: $10.1095 /$ biolreprod.107.060558

Weiss, W.P., Wyatt, D.J. (2004) Digestible energy values of diets with different fat supplements when fed to lactating dairy cows. J Dairy Sci, 87(5). 1446-1454.

DOI: $10.3168 /$ ids.s0022-0302(04)73295-6

Whitlock, L.A. (2002) Feeding fish meal and extruded soybeans enhances the conjugated linoleic acid (CLA) content of milk. J Dairy Sci, 85(3). 624-631.

DOI: $10.3168 /$ jds.s0022-0302(02)74116-7 